Marine Geology

March 2006; 227(3-4) : 163-176

http://dx.doi.org/10.1016/j.margeo.2005.12.006

(C) 2006 Elsevier B.V. All rights reserved
Archimer, archive institutionnelle de l'Ifremer http://www.ifremer.fr/docelec/

\title{
Multiple bottom-simulating reflections in the Black Sea: Potential proxies of past climate conditions
}

\author{
Irina Popescu ${ }^{\mathrm{a}, \mathrm{b}}$, Marc De Batist ${ }^{\mathrm{a}}$, Gilles Lericolais ${ }^{\mathrm{c}}$, Hervé Nouzéc ${ }^{\mathrm{c}}$, Jeffrey Poort ${ }^{\mathrm{a}}$, \\ Nicolae Panin ${ }^{\mathrm{b}}$, Wim Versteeg $^{\mathrm{a}}$ and Hervé Gillet ${ }^{\mathrm{c}}$
}

\author{
${ }^{\mathrm{a}}$ Renard Centre of Marine Geology (RCMG), Universiteit Gent, Krijgslaan 281 S8, B-9000 Gent, Belgium \\ ${ }^{b}$ GeoEcoMar Bucharest, Str. D. Onciul 23-25, RO-024053, Romania \\ 'IFREMER Brest, DRO/GM LES, BP 70, F-29280 Plouzané, France \\ *: Corresponding author : irinapopescu@yahoo.com
}

\begin{abstract}
A previously unknown pattern of multiple bottom-simulating reflections (BSRs) occurs on high-resolution reflection seismic data in the Danube deep-sea fan, associated with acoustic features indicating free gas. Our study provides evidence that this pattern is developed in relation with the architecture of distinct channel-levee systems of the Danube fan. Channel-levee systems hosting multiple BSRs act as relatively sealed gas-bearing systems whose top is situated above the base of the gas hydrate stability zone (BGHSZ). Inside these systems, free gas accumulates below the BGHSZ under a combined lithological, structural and stratigraphical control.
\end{abstract}

The uppermost BSR marks the current equilibrium BGHSZ, for a gas composition of more than $99 \%$ methane. Model-derived depths of the BGHSZ for different gas compositions and pressuretemperature conditions show that multiple BSRs would correspond to the BGHSZ either for (1) layers of gas hydrates with high contents of heavy hydrocarbons or hydrogen sulphide, or (2) stable climatic episodes with temperatures between glacial values and the present-day conditions. As the gas hydrate compositions required by hypothesis (1) are in sharp contradiction with the general background of the gas composition in the study area, we suggest that multiple BSRs are most probably relics of former positions of the BGHSZ, corresponding to successive steps of climate warming. In this case, they can provide sea-bottom paleotemperature values for these episodes, and hence they are potential new proxies for deciphering past climate conditions.

Keywords: bottom-simulating reflections; gas hydrates; gas; seismic data; deep-sea fan; Black Sea 


\section{Introduction}

Gas hydrates are crystalline solid compounds consisting of a gas molecule surrounded by a cage of water molecules, that form under specific conditions of high pressure and low temperature. They occur either on land in polar settings associated with permafrost, or in oceanic sediments along continental margins. The depth of the hydrate layer is limited by temperature increasing with depth, in relation with the local geotermal gradient. Many gases may form hydrates (including several low-carbon-number hydrocarbons, carbon dioxide, nitrogen, and hydrogen sulphide), but most natural gas hydrates consist mainly of methane (Kvenvolden, 1995). General interest currently focusing on gas hydrates in marine sediments is mainly due to: (1) the environmental consequences of gas releasing at the seafloor, as a possible contributor to the greenhouse effect, (2) their impact on the seafloor stability, as a potential submarine geohazard, and (3) the fuel resource potential of the gas hydrates, as they contain a great volume of methane.

Bottom-simulating reflections (BSRs) are the typical seismic signature for most oceanic occurrences of gas hydrates. They consist of a reversed polarity reflection that approximately parallels the sea floor and crosscuts the acoustic bedding structure of the sediments. The presence of a free gas zone beneath the BSR is attested by high reflectivity and has been confirmed by drilling (e.g. MacKay et al., 1994; Holbrook et al., 1996; Taylor et al., 2000). It is currently considered that the BSR reflects the acoustic impedance contrast at the interface between sediments containing gas hydrates and the underlying low-velocity gas-charged sediments, and that it thus marks the base of the gas hydrate stability zone (BGHSZ). 
Uncommon double BSRs have been reported on the Norwegian margin (Posewang and Mienert, 1999; Andreassen et al., 2000), in the Nankai Trough off central Japan (Matsumoto et al., 2000; Foucher et al., 2002; Baba and Yamada, 2004) and at Hydrate Ridge on Cascadia continental margin (Shipboard Scientific Party ODP Leg 204, 2002; Bangs et al., 2005). While the upper BSR is generally interpreted to represent the current BGHSZ, the origin of the lower BSR has remained controversial. Several interpretations have been proposed, such as a relic of a former position of the BGHSZ (Posewang and Mienert, 1999; Matsumoto et al., 2000; Foucher et al., 2002; Baba and Yamada, 2004; Bangs et al., 2005), a current equilibrium feature associated with layers of gas hydrates with distinct compositions (Posewang and Mienert, 1999; Andreassen et al., 2000), or the lower boundary of a transitional zone between gas hydrates and free gas (Baba and Yamada, 2004). Alternatively, other processes not associated with gas hydrates such as transition from opal-A to opal-CT may create a normal-polarity diagenesis-related BSR (Hein et al., 1978; Berndt et al., 2004).

Here we present the first occurrence of an exceptional pattern with multiple BSRs on the northwestern margin of the Black Sea. Our study provides evidence that this pattern is related to the architecture of the Danube deep-sea fan, and analyses the origin of multiple BSRs, attempting to define the potential significance of this finding for marine geological research.

\section{Regional background}

Our study area is located on the northwestern margin of the Black Sea, downslope of the shelfbreak (Fig. 1). The sedimentary architecture of this zone is marked by the presence of a major turbidite system: the Danube deep-sea fan. The Danube fan is a large mud- 
rich fan, essentially composed of a succession of stacked channel-levee systems that are emplaced during successive sea-level lowstands (Wong et al., 1994; Popescu et al., 2001). Typically, channel-levee systems in mud-rich fans are lenticular sedimentary units with coarse-grained sediments at the channel axis, and finer-grained, wellstratified alternations of sand and mud in the lateral levees (Manley et al., 1997; Normark et al., 1997). Only one channel-levee system in the Danube fan was active at a time. The most recent system is the Danube channel, that overlays other channel-levee systems and is directly connected to the Danube canyon (Popescu et al., 2001; Fig.1). Fan growth is interrupted since the last sea-level rise (Popescu et al., 2001).

Gas hydrate occurrence in the Danube fan has been known since the first hydrate discovery in shallow subbottom sediments (Yefremova and Zhizhchenko, 1974, cited in Ginsburg and Soloviev, 1998). More recently, the presence of gas hydrates in deep sediments was inferred from BSR observations in the southern part of the fan (du Fornel, 1999; Ion et al., 2002). It was suggested that these hydrates have a biogenic origin. However, information on this topic is rather limited (see Ginsburg and Soloviev, 1998 for a review). To date, other analyses of hydrates in this area are not available.

\section{Data and methods}

Our investigation is based on high-resolution reflection seismic data acquired during the BlaSON surveys of IFREMER and GeoEcoMar (1998 and 2002). Data were obtained using consecutively two seismic sources: a GI gun (central frequency $70 \mathrm{~Hz}$ ) and a miniGI gun (central frequency $150 \mathrm{~Hz}$ ). The receiver was a 24-channel streamer, $300 \mathrm{~m}$ long. We processed the data using Landmark's ProMAX software. The conventional processing flow included CDP gather formation, velocity analysis, removal of noisy 
traces, normal moveout correction and stack, migration, and seabed mute. No amplitude corrections were applied. Analysis of seismic attributes and trace visualization were done using Seismic Microsystems’ Kingdom Suite software.

We used modeling to determine the depth of the BGHSZ under different pressuretemperature (P-T) conditions. Modeling is based on calculation of (1) hydrate stability curves using the CSMHYD program (Sloan, 1998), and (2) temperature lines corresponding to a linear geothermal gradient of $30 \% / \mathrm{km}$ based on the Black Sea geothermal database (Vassilev and Dimitrov, 2002), for a seafloor temperature of $9.1^{\circ} \mathrm{C}$ determined by SIPPICAN measurements during BLASON cruises (Lericolais, 2002). Intersection of (1) and (2) corresponds to the BGHSZ.

Pore water salinity is an important parameter for evaluating the hydrate stability conditions. Presently, the Black Sea has a salinity of $17.5 \%$ in surface waters and 22.3\%o in deep waters (Murray et al., 1991). Still, pore-water and diatoms analyses from DSDP 42B drilling in the central Black Sea showed dominant fresh water stages in the Quaternary deposits, corresponding to phases of isolation of the Black Sea (Ross, 1978). This is in agreement with fauna analysis for the last glacial indicating a salinity of ca. 5\%o (Chepalyga, 1985). Knowing that deposition in the Danube fan occurred essentially during lacustrine lowstands, and was quasi-interrupted during marine highstands (Wong et al., 1994), we assumed a mean pore water salinity value of 5\%.

Acoustic velocity in sediments could not be precisely evaluated due to technical characteristics of the acquisition system (too short streamer). To convert travel-time in depth, we considered minimum and maximum velocity values of $1600 \mathrm{~m} / \mathrm{s}$ and 1800 $\mathrm{m} / \mathrm{s}$ respectively, in agreement with velocity analysis in similar environments (Posewang and Mienert, 1999; Lüdmann et al., 2004). 


\section{Results}

\subsection{BSRs and gas-related seismic facies}

We mapped three areas of BSR occurrence in the Danube fan, located between $750 \mathrm{~m}$ and 1830 m water depth (A, B, C in Fig. 1). In the zones A and B, situated in the southern part of the fan, we detected an unusual succession of two, three or four BSRtype distinct reflections with similar amplitude, all of them sub-parallel to the seafloor, showing reversed polarity and crosscutting the sedimentary structure (Figs. 2A, 3, 4, 5; Figs. SM1, SM2, SM3 in suppl. mat.). A fifth very weak and discontinuous BSR possibly lies below the four-BSR occurrence (Fig. 2A, 5). The depth of each BSR increases with water depth, and thus with pressure. The uppermost BSR (BSR1) continues laterally as the upper limit of an area containing seismic reflections of anomalously high amplitude, underlain by acoustic turbidity (Figs. 2A, 3, 4). Small patches of enhanced reflections also appear below lower BSRs. In the northern zone C, the BSR appears either as a defined reflection with reversed polarity, or as an upper limit of enhanced reflections, mimicking the seafloor (Fig. 6). A faint double BSR occurs locally below the widespread BSR1 (Fig. 6). As a general rule, the BSRs are less clear on data acquired with a higher frequency source (Figs. 3 and 6) as compared with lower frequency data (Figs. 2 and 4), which is in agreement with previous multifrequency studies of the BGHSZ (e.g. Vanneste et al., 2001). A low-frequency conventional industry-seismic profile across the zone C shows that the two BSRs have a reversed polarity (C. Dinu, personal communication, 2005). They are thus similar to BSRs in areas $\mathrm{A}$ and $\mathrm{B}$. 
This association of BSRs, enhanced reflections and acoustic turbidity indicates the presence of gas hydrates and free gas in the sediment pore space (e.g. Taylor et al., 2000). BSR1 and its prolongation along the bottom-simulating boundary at the top of the enhanced reflections are interpreted to represent the limit between gas hydrates and free gas, and thus the current BGHSZ (Fig. 2B). High amplitude anomalies located beneath this interface suggest that free gas occurs under the gas hydrate-bearing sediments (Fig. 2). Interestingly, amounts of free gas below lower BSRs are locally attested by segments of enhanced reflections that change amplitude where they cross multiple BSRs (Figs. 5, SM1). This gas appears to focus along specific sedimentary horizons, probably in relation with their higher permeability. High amounts of free gas are not required to create these reflections, as gas concentration may be as low as a few per cent of the sediment pore space.

\subsection{Linking multiple BSRs to geological background}

Gas and hydrate seismic features show an obvious relationship with the architecture of the Danube deep-sea fan. Occurrences of gas and hydrates correspond to specific channel-levee systems (A, B, C in Fig. 1). In all cases: (1) the BGHSZ is visible only on a limited segment inside the channel-levee system, (2) multiple BSRs crosscut the parallel horizons of the levee that is situated downslope of the channel axis (considering the present seafloor gradient) and terminate against the base of the channel-levee system, and (3) free gas accumulation corresponds to the channel axis area (Figs. 2, 3, 4). This gas facies masks the channel deposits, and is different from High Amplitude Reflections (HAR seismic facies) strictly confined at the channel axis, that typically 
characterize these deposits in channel-levee systems with no indication of gas (see figures 3 and 5 in Popescu et al., 2001).

Multiple BSRs in the Danube fan occur exclusively as part of a defined pattern: a gasbearing channel-levee system whose top is situated above the BGHSZ (Fig. 2b). This pattern is developed around a gas accumulation at the channel axis corresponding to coarser-grained deposits with higher porosity, and thus reflecting a lithological control. Trapping gas inside this particular channel reservoir was favored by burial under the fine-grained stratified levees of the subsequent system, which resulted in the formation of relatively sealed isolated gas-bearing systems. Additionally, the typical lenticular shape of the channel-levee systems created topographic highs only partially buried, resulting in an anticlinal BGHSZ (Fig. 2) that is able to form a structural trap for free gas (Kvenvolden, 1998). In the lateral levees, free gas concentrates where the stratified deposits are sealed up-dip by the BGHSZ in a stratigraphic type gas trap (Fig. 2; Kvenvolden, 1998).

We can thus define a specific pattern of relatively closed gas and hydrate accumulations under a combined lithological, structural and stratigraphic control. This pattern represents the background for the formation of multiple BSRs, and most probably influences the multiple BSR-forming processes. We would argue that similar patterns could occur as well in other deep-sea fans in the World Ocean if sufficient amounts of gas are available, eventually including multiple BSRs.

\section{Discussion: origin of multiple BSRs}

\subsection{Characteristics of multiple BSRs}


The occurrence of multiple BSRs proves that the processes at the BGHSZ are more complex than previously thought. As shown above, interpretation of the seismic facies indicates that the upper BSR1 represents the active BGHSZ. To verify this interpretation, we calculated the theoretical depth of the BGHSZ under the present conditions for different gas compositions in a fresh pore water system (5\%) (Fig. 7A). Because pore water salinity is an important parameter that is based on general information at the basin scale and not on direct measurements in the study area (see section 3) we also checked the stability curves for minimum (0\%o) and maximum (35\%o) salinity values, and the reliability of the assumed value of 5\%o (Fig. 7B). Calculations showed that BSR1 is consistent with the equilibrium BGHSZ under the present-day conditions for a gas composition of more than $99 \%$ methane, and for fresh pore water (salinity $0-5 \%$, Fig. 7). This result is in agreement with the common interpretation of the upper BSR in all double BSRs occurrences (Posewang and Mienert, 1999; Matsumoto et al., 2000; Foucher et al., 2002; Baba and Yamada, 2004; Bangs et al., 2005).

As regards lower BSRs, they clearly do not represent seismic artifacts, given that we identified multiple BSRs consistent in pattern across the study area, on data acquired with different sources at different times. Several common points exist between our multiple pattern and previous observations of double BSRs:

a. The lower BSR mimics the classic equilibrium BSR (Posewang and Mienert, 1999; Matsumoto et al., 2000; Foucher et al., 2002; Baba and Yamada, 2004; Bangs et al., 2005). Also in our case, multiple BSRs have a similar location and water-depth dependence as the upper hydrate-related BSR, which implies that the forming process is pressure and temperature controlled in a similar fashion. In addition, sub-bottom depth 
of multiple BSRs increasing with water depth clearly distinguishes them from opalA/opal-CT BSRs that show a constant depth below the seafloor (Berndt et al., 2004). Consequently, our results confirm that the formation of multiple BSRs is caused by processes involving gas hydrates.

b. The lower BSR usually has a reversed polarity compared with the sea floor, similar to the classic BSR (Matsumoto et al., 2000; Foucher et al., 2002; Baba and Yamada, 2004; Bangs et al., 2005). Likewise, all multiple BSRs in our pattern show reversed polarity (Fig. 5). The reversed polarity reflects a negative acoustic impedance contrast, which for the equilibrium BSR is associated with low velocity free gas below the BGHSZ (Holbrook et al., 1996). The only exception is the case reported by Posewang and Mienert (1999) showing normal polarity. However occurrence of free gas beneath the lower BSR is suggested by low velocities (Andreassen et al., 2000). In our case, enhanced reflections are sometimes located below multiple BSRs, and indicate that amounts of free gas may lie beneath lower BSRs (Fig. 5; Fig. SM1 in suppl. mat.). We thus infer that the presence of free gas below the surfaces corresponding to multiple BSRs contributes to create these reflections. Furthermore, this evidence requires that the multiple BSR-forming process should be able to account for the occurrence of this gas.

c. Lithological information about the sediments hosting the double BSRs (Shipboard Scientific Party ODP Leg 204, 2002; Baba and Yamada, 2004) shows a type of sedimentary facies similar to our case: mud-dominated stratified sediments with intercalations of sand. This convergence suggests that the mechanisms causing the multiple BSRs should be compatible with this specific facies.

Beyond these common points, the multiple BSRs in the Danube fan show remarkable particular characteristics that may contribute to advance understanding of these features: 
a. Multiple BSRs occur as groups of successive reflections, implying that the process that produced them has a repetitive character. In addition, this feature is in contradiction to the idea that double BSRs could represent the boundaries of a transitional zone between hydrates and free gas, as proposed by Baba and Yamada (2004).

b. Multiple BSRs form in relatively isolated gas-bearing systems, controlled by the architecture of the Danube deep-sea fan deposits. As the formation of gas hydrates in partially closed systems may lead to specific physical changes to the sediment (Clennell et al., 1999), these conditions need to be considered in the investigation of the processes forming multiple BSRs.

Based on these features, the origin of the lower BSRs can be theoretically explained by two alternative hypotheses: (1) they are equilibrium features reflecting layers of gas hydrate with distinct compositions, or (2) they represent paleo-BSRs associated with former positions of the BGHSZ (Posewang and Mienert, 1999). However, in practice, there is currently no evidence reported in the literature concerning either the stratification of gas hydrates with different compositions, or the preservation of the BGHSZ remnants after changes of P-T conditions. Moreover, drilling at a double BSR site on Hydrate Ridge did not conclusively resolve this problem: analysis of the gas composition do not support the hypothesis of stratified gas hydrates (Shipboard Scientific Party ODP Leg 204, 2002), but this may be due to unspecific sampling and/or gas disturbances (G. Bohrmann, personal communication, 2004). Consequently, until new direct information becomes available, any discussion on this topic is inevitably limited to theoretical assumptions. Under these circumstances, we used modeling to test the compatibility of these alternative hypotheses against the generally known background of multiple BSR occurrences. 


\subsection{Are multiple BSRs current equilibrium features?}

The hypothesis that the multiple BSRs could be current simultaneously active features is based on the fact that different gas compositions correspond to different depths of the BGHSZ (Sloan, 1998). Multiple BSRs would thus represent the bases of successive layers of hydrates with distinct compositions. In principle, gas hydrates may contain small hydrocarbons (methane, ethane) and non-hydrocarbons $\left(\mathrm{N}_{2}, \mathrm{CO}_{2}, \mathrm{H}_{2} \mathrm{~S}\right)$ in structure I, but also heavier hydrocarbons in structures II and H. In reality most natural hydrates in deep marine sediments are composed mainly by methane (>99\%) in structure I, commonly with a microbial origin (Kvenvolden, 1995). Nevertheless, thermogenic gas hydrates with high amounts of heavier hydrocarbons have been described in near surface sediments in association with deep migration, from oil provinces in the Golf of Mexico (Sassen et al., 2001) and from mud volcanoes in the Caspian Sea (Ginsburg and Soloviev, 1997). Mixtures in different proportions of microbial and thermogenic gas commonly occur, and gas hydrates with distinct origins sometimes coexist in the same accumulation (e.g. Milkov et al., 2005). Also, gas hydrates composed of methane and $\mathrm{H}_{2} \mathrm{~S}$ have been found on the northern Hydrate Ridge, in shallow sediments confined to the active sulphate reduction zone (Kastner et al., 1998).

Hydrate composition is clearly a complex parameter. Nevertheless our model was forced with the general background of the gas hydrate composition in the study area. Gas hydrates in the Black Sea consist mainly of methane, with variable amounts of $\mathrm{CO}_{2}$ and $\mathrm{N}_{2}$ (reviewed by Vassilev and Dimitrov, 2002). Higher hydrocarbons occur in hydrates associated with mud volcanoes, still methane is the main component: 93.3- 
99.9\% in the central Black Sea (Ginburg and Soloviev, 1998) and $>99.5 \%$ in the Sorokin Trough (Blinova et al., 2003). Although gas hydrate sampled in shallow subbottom sediments in the Danube fan was considered to form from in situ biogenic methane (Ginburg and Soloviev, 1998), direct analyses of the hydrate composition in this area are not available. Concerning gas content in deep sediments, analysis of DSDP $41 \mathrm{~B}$ cores in the southern Black Sea indicated biogenic methane and $\mathrm{CO}_{2}$, sometimes including traces of ethane decreasing with depth (Ross, 1978).

To test the hypothesis of the equilibrium BSRs we calculated the depth of the BGHSZ under the present P-T conditions, for different hydrate compositions consisting in mixtures of methane and $\mathrm{CO}_{2}, \mathrm{~N}_{2}, \mathrm{H}_{2} \mathrm{~S}$ respectively (Table 1 in suppl. mat., Fig. 8A), and in variable mixtures of methane, ethane and propane (Table 2 in suppl. mat., Fig. 8B). Our results show that the BGHSZ depth is not significantly affected by the presence of $\mathrm{CO}_{2}$, and slightly rises with increasing content of $\mathrm{N}_{2}$ (Fig. 8A). The components that may account for lowering the BGHSZ to the depth of BSR4 are (Fig. 8):

- $\mathrm{H}_{2} \mathrm{~S}$ (at 5.1-5.6\%), and

- ethane C2 (at 26.3-28.5\%), or mixtures including significant amounts of higher hydrocarbons, such as propane C3 (5\% C3 + 17 to 23.5\% C2 in structure II, or 5\% C3 + 37.4 to 47.2 C2 in structure I; and 10\% C3 + 32 to 34.3\% C2 in structure II, or $10 \%$ C3 + 46 to $50 \%$ C2 in structure I).

Consequently, the lower BSRs would correspond either to mixed methane- $\mathrm{H}_{2} \mathrm{~S}$ hydrates, or to hydrates with major contents of higher hydrocarbons. None of these options is in agreement with the generally reported composition of gas hydrates in the Black Sea. Moreover, the occurrence of deep layers of gas hydrates with such 
compositions was not attested so far by hydrate samples recovered from deep drilling, as they always contain $>99 \%$ methane (Kvenvolden, 1995). An additional dilemma is the potential process that could separate gas mixtures in up to five discrete compositions through the same sediments, with a top layer of more than 99\% methane and coexisting laterally with unseparated gas. In this respect, we consider that the formation of multiple BSRs as active phase boundaries separating hydrates with different compositions is highly unlikely. However, as long as data from drilling through the

multiple BSRs are not available, to specify the gas composition of deep hydrate samples, this hypothesis remains theoretically valid.

\subsection{Are multiple BSRs relict features?}

Alternatively, multiple BSRs may represent paleo-BSRs associated with former positions of the BGHSZ. In this case, they would be relict features that marked periods of steady state in the P-T conditions. Shifting of the BGHSZ between two stable episodes reflects P-T changes. If pressure variations have a quasi-instantaneous effect, temperature change at the seafloor propagates gradually through the sediment, so that stable P-T conditions would be marked at the BGHSZ with a constant time delay. Generally, P-T changes are in relation with global climatic cycles, local variations of the sediment load, or tectonic uplift. Our model does not consider recent tectonic uplift that was not attested in the Black Sea. Likewise, we assumed that sediment load above multiple BSRs was constant because they are located distally or outside the most recent depositional area corresponding to the Danube channel. In contrast, climatic changes causing sea level and bottom temperature variations obviously represented a major control on the P-T variations at the seafloor. 
Commonly, it is considered that sea bottom temperatures of the glacial ocean were lower than today by $2-5^{\circ} \mathrm{C}$ (e.g. $2.6-4.3^{\circ} \mathrm{C}$ in Labeyrie et al., $1992 ; 2-4.4^{\circ} \mathrm{C}$ in Adkins et al., 2002). A rapid warming with up to $5^{\circ} \mathrm{C}$ after the Younger Dryas is described on the Norwegian margin by Mienert et al. (2005). For the Black Sea this type of information is currently unavailable. As regards the sea level variations, the recent history of the Black Sea is a succession of phases of isolation and reconnection to the open ocean, whose timing and amplitude are still heavily disputed (reviewed in Popescu et al., 2004). Nevertheless, all estimates are situated 0 to $150 \mathrm{~m}$ below the present day level. Accordingly, in order to determine potential former P-T conditions corresponding to multiple BSRs, we calculated the depth of the BGHSZ for sea floor temperatures 0 to $5^{\circ} \mathrm{C}$ lower than today, and for sea levels between 0 and $-150 \mathrm{~m}$, considering a gas hydrate composition of more than 99\% methane (Table 3 in suppl. mat.). The resulting diagram shows the variation of the BGHSZ depth with the temperature change for a given sea level, and defines temperature changes that are needed to lower the BGHSZ at the depth of each multiple BSR (Fig. 9). This diagram indicates that for any sea level between 0 and -150 , a sea floor paleotemperature $3.6-4.6^{\circ} \mathrm{C}$ lower than today would correspond to the lowermost BSR4. Similarly, BSR3 represents the equilibrium BGHSZ for bottom temperatures $2.9-3.9^{\circ} \mathrm{C}$ below the present one, whereas BSR2 corresponds to a $1.6-2.6^{\circ} \mathrm{C}$ cooling. Assuming that BSR2 corresponds to the last Black Sea lowstand (90 m, Popescu et al., 2004), bottom paleotemperature for this episode should be 1.92.4 ${ }^{\circ} \mathrm{C}$ lower than today (Fig. 9).

These model-derived temperature changes are in the range of values indicated by studies of the glacial bottom temperatures in the World Ocean (Labeyrie et al., 1992; Adkins et al., 2002). Therefore, our results show that multiple BSRs are compatible 
with successive steps of stable climatic episodes, with temperatures between glacial values and the present-day conditions. The main question that arises from this finding regards the possible processes that may lead to the preservation of former BGHSZ after shifting of the equilibrium conditions. Normally, when the BGHSZ moves upward hydrate destabilization introduces free gas above the old BSR, which could destroy impedance contrast and thus reflectivity. However, this gas would tend to migrate upward to the new HSZ (cf. methane recycling process of Paull et al., 1994). In our case, this migration appears to be directed up-dip along the stratification planes, to concentrate beneath the subsequent BSR (Fig. 2). As amounts of free gas are preserved beneath the old BSR (Fig. 2), different concentrations of gas above and below this surface probably account for the conservation of the acoustic impedance contrast.

The preservation of free gas beneath a paleo-BSR after the upward shift of the BGHSZ is a puzzling feature. To explain it, Foucher et al. (2002) calculated the duration of persistence of a reflective free gas layer assuming no advective transport, and obtained a maximum of ca. 10000 years. Also, Bangs et al. (2005) showed that, under little or no fluid advection, free gas below a paleo-BSR could remain stable enough to prevent BSR from dispersing quickly by diffusion. We though feel that in our case, this mechanism alone could hardly explain the coexistence of up to 4 BSRs preserved at the same degree. Alternatively, Posewang and Mienert (1999) inferred that an enigmatic diagenetic process could have marked a former BGHSZ. To date, diagenetic effects of gas hydrates on hosting sediments are poorly known, still several studies outlined different aspects such as formation of authigenic siderite from decomposition of methane hydrate (Matsumoto, 1989), diagenesis of magnetic minerals (Housen and Musgrave, 1996) or physical changes associated with the presence of hydrates, like 
dewatering (Clennell et al., 1999) and permeability clogging at the BGHSZ (Nimblett and Ruppel, 2003).

Based on the main characteristics of multiple BSRs (section 5.1.), this process should be able (1) to act at the BGHSZ, (2) to be able to account for the localised presence of free gas in specific sedimentary strata, (3) to affect fine-grained sediments (mud with sand intercalations), and (4) to occur repeatedly. Also, its development appears to be related to relatively closed gas-bearing systems. The formation of gas hydrates in such systems may lead to water depletion in the host sediments, resulting in changes of the physical properties of the sediment (i.e. overconsolidation, Clennell et al., 1999), and possibly in the formation of permanent permeability seals. In addition, other types of dewateringrelated processes may occur. A likely candidate could be the smectite-to-illite reaction that is known to provide a seal for fluid migration in clay-rich sediments (Freed and Peacor, 1989). Although dehydration of smectite typically occurs at temperatures and/or pressures higher than those characterizing the BGHSZ, recent studies evidenced that this reaction can be also microbially promoted and develop rapidly under low P-T conditions (Kim et al., 2004). However, to our knowledge, a hydrate-related occurrence of the smectite-to-illite reaction has not been demonstrated so far. Clarification of the preservation mechanisms of former positions of the BGHSZ is a complex question, and further information from drilling is indispensable to answer it conclusively.

Nevertheless, the above lines of evidence suggest that the hypothesis of multiple paleoBSRs is the most plausible in our case. Therefore, multiple BSRs can be regarded as potential frozen proofs of former environmental conditions, able to provide sea-bottom paleotemperature values for distinct stable climatic episodes. Our model shows that for a given gas composition and any sea level, the paleotemperature at the sea floor 
corresponding to a multiple BSR can be evaluated within an error margin of $1^{\circ} \mathrm{C}$ (Fig. 9). Uncertainty can be largely reduced through better definition of parameters, when further information (such as acoustic velocity) becomes available.

\section{Conclusions}

Our results provide evidence that multiple BSRs occur at several locations in the Danube fan, and that they are consistent in pattern across the study area. This pattern is developed in relation with the architecture of distinct channel-levee systems that act as relatively sealed gas-bearing systems. Free gas accumulation beneath the current BGHSZ is controlled lithologically (by the coarser grained deposits at the channel axis), structurally (by the anticlinal shape of the BGHSZ) and stratigraphically (by up-dip sealing of the stratified levees).

The uppermost BSR represents the active BGHSZ, as shown by the absence of free gas above this BSR, combined with its pressure-depth behaviour and reversed polarity. Model-derived depth of the BGHSZ is consistent with this interpretation for a gas composition of more than 99\% methane. Characteristics of the lower BSRs indicate that their forming mechanism involved the presence of gas hydrates. Free gas occurs locally beneath each multiple BSR, and most probably contributes to create these reflections. As direct information from drilling is not available, the origin of multiple BSRs was evaluated based on modeling of the BGHSZ depth. Our results show that multiple BSRs are most probably relics of former positions of the BGHSZ, corresponding to stable cold climatic episodes. In this case, they may represent valuable keys to our understanding of the global climatic history. 


\section{Acknowledgements}

This study has been supported by a Marie Curie Fellowship of the European Community programme IHP under contract number HPMF-CT-01835 (I.P.). Data acquisition was financed through the French-Romanian Cooperation Programme of IFREMER and GeoEcoMar (BlaSON). We also acknowledge support from the ECfunded ASSEMBLAGE Project (EVK3-CT-2002-00090). Constructive comments from Graham Westbrook and an anonymous reviewer considerably improved this paper. Thanks are also due to Gerhard Bohrmann, William Dillon and Ben Clennell for their useful suggestions on a previous version of this manuscript.

\section{References}

Adkins, J. F., McIntyre, K., Schrag, D. P., 2002. The salinity, temperature and $\delta^{18} \mathrm{O}$ of the glacial deep ocean. Science 298, 1769-1773.

Andreassen, K., Mienert, J., Bryn, P., Singh, S.C., 2000. A double gas-hydrate related bottom-simulating reflector at the Norwegian continental margin. Ann. N.Y. Acad. Sci. 912, 126-135.

Baba, K., Yamada, Y., 2004. BSRs and associated reflections as an indicator of gas hydrate and free gas accumulation: an example of accretionary prism and forearc basin system along the Nankai Trough, off central Japan. Resour. Geol. 54, 11-24.

Bangs, N. L. B., Musgrave, R. J., Trehu, A., 2005. Upward shifts in the southern Hydrate Ridge gas hydrate stability zone following postglacial warming, offshore Oregon. J. Geophys. Res. 110, B03102. 
Berndt, C., Bünz, S., Clayton, T., Mienert, J., Saunders, M., 2004. Seismic character of bottom-simulating reflections: examples from the mid-Norwegian margin. Mar. Petr. Geol. 21, 723-733.

Blinova, V. N., Ivanov, M. K., Bohrmann, G., 2003. Hydrocarbon gases in deposits from mud volcanoes in the Sorokin Trough, north-eastern Black Sea. Geo-Mar. Lett. 23, 250-257.

Chepalyga, A. L., 1985. Inland sea basins, in: Velichko, A. A. (Ed.), Late Quaternary environments of the Soviet Union. University of Minnesota Press, Minneapolis, pp. 229-247.

Clennell, M. B., Hovland, M., Booth, J. S., Henry, P., Winters, W. J., 1999. Formation of natural gas hydrates in marine sediments, 1 . Conceptual model of gas hydrate growth conditioned by host sediment properties. J. Geophys. Res. 104, 22985-23003.

du Fornel du Roure de Paulin, E., 1999. Architecture du cône profond du Danube en sismique reflexion 2D. M.Sc. dissertation, Université Montpellier II, 46 pp.

Foucher, J. P., Nouzé, H., Henry, P., 2002. Observation and tentative interpretation of a double BSR on the Nankai slope. Mar. Geol. 187, 161-175.

Freed, R. L., Peacor, D. R., 1989. Geopressured shale and sealing effect of smectite to illite transition. AAPG Bull. 73/10, 1223-1232.

Ginsburg, G. D., Soloviev V. A., 1997. Methane migration within the submarine gashydrate stability zone under deep-water conditions. Mar. Geol. 137, 49-57.

Ginsburg, G. D., Soloviev, V. A., 1998. Submarine gas hydrates, VNIIOkeangeologia, St. Petersburg, 216 pp. 
Hein, J. R., Scholl, D. W., Barron, J. A., Jones, M. G., Miller, J., 1978. Diagenesis of late Cenozoic diatomaceous deposits and formation of the bottom simulating reflector in southern Bering Sea. Sedimentology 25, 155-181.

Holbrook, W. S., Hoskins, H., Wood, W. T., Stephen, R. A., Lizarralde, D., Leg 164 Science Party, 1996. Methane Hydrate and Free Gas on the Blake Ridge from Vertical Seismic Profiling. Science 273, 1840-1843.

Housen B. A., Musgrave R. J., 1996. Rock-magnetic signature of gas hydrates in accretionary prism sediments. Earth Planet. Sci. Lett. 139, 509-519.

Ion, G., Lericolais, G., Nouzé, H., Panin, N., Ion, E., 2002. Seismo-acoustic evidence of gases in sedimentary edifices of the paleo-Danube realm. CIESM Workshop Series 17, 91-95.

Kastner, M., Kvenvolden, K. A., Lorenson, T. D., 1998. Chemistry, isotopic composition, and origin of a methane-hydrogen sulfide hydrate at the Cascadia subduction zone. Earth Planet. Sci. Lett. 156, 173-183.

Kim, J., Dong, H., Seabaugh, J., Newell, S. W., Eberl, D. D., 2004. Role of microbes in the smectite-to-illite reaction. Science 303, 830-832.

Kvenvolden, K. A., 1995. A review of the geochemistry of methane in natural gas hydrate. Org. Geochem. 23, 997-1008.

Kvenvolden, K. A., 1998. A primer on the geological occurrence of gas hydrate, in: Henriet, J.-P., Mienert, J. (Eds.), Gas Hydrates: Relevance to World Margin Stability and Climate Change. Geol. Soc. London Spec. Publ. 137, pp. 9-30.

Labeyrie, L. D., Duplessy, J.-C., Duprat, J., Juillet-Leclerc, A., Moyes, J., Michel, E., Kallel, N., Shackleton, N. J., 1992. Changes in the vertical structure of the North Atlantic Ocean between glacial and modern times. Quaternary Sci. Rev. 11, 401-413. 
Lericolais, G., 2002. BLASON 2 report (available at http://www.ifremer.fr/sismer/catal/campagne/campagne.htql?crno=2020070).

Lüdmann, T., Wong, H. K., Konerding, P., Zilmer, M., Petersen, J., Flüh, E., 2004. Heat flow and quantity of methane deduced from a gas hydrate field in the vicinity of the Dniepr canyon, northwestern Black Sea. Geo-Mar. Lett. 24, 182-193.

MacKay, M. E., Jarrard, R.D., Westbrook, G.K., Hyndman, R.D., Shipboard Scientific Party of ODP Leg 146, 1994. Origin of bottom-simulating reflectors: Geophysical evidence from the Cascadia accretionary prism. Geology 22, p. 459-462.

Manley, P. L., Pirmez, C., Busch, W., Cramp, A., 1997. Grain-size characterization of Amazon fan deposits and comparison to seismic facies units, in: Flood, R.D., Piper, D.J.W., Klaus, A., Peterson, L.C. (Eds.), Proc. ODP Sci. Results 155, pp. 35-52.

Matsumoto, R., 1989. Isotopically heavy oxygen-containing siderite derived from the decomposition of methane hydrate. Geology 17, 707-710.

Matsumoto, R., Masuda, M., Foucher, J., Tokuyama, H., Ashi, J., Tomaru, H., 2000. Double BSR in the Eastern Nankai Trough: fact or artifact. AGU 2000 Western Pacific Geophys. Meeting (available at http://www.agu.org/meetings/waiswp00.html).

Mienert, J., Vanneste, M., Bünz, S., Andreassen, K., Haflidasson, H., Sejrup, H. P., 2005. Ocean warming and gas hydrate stability on the mid-Norwegian margin at the Storegga Slide. Mar. Petr. Geol. 22, 233-244.

Milkov, A. V., Claypool, G. E., Lee, Y.-L., Sassen, R., 2005. Gas hydrate systems at Hydrate Ridge offshore Oregon inferred from intermolecular and isotopic properties of hydrate-bound and void gases. Geochim. Cosmochim. Acta 69, 1007-1026.

Murray, J., Top, W. Z., Özsoy, E., 1991. Hydrographic properties and ventilation of the Black Sea. Deep-Sea Res. 38, Suppl.2, S663-S689. 
Nimblett, J., Ruppel, C., 2003. Permeability evolution during the formation of gas hydrates in marine sediments. J. Geophys. Res. 108 B9 2420.

Normark, W. R., Damuth, J.E., and the Leg 155 Sedimentology Group, 1997. Sedimentary facies and associated depositional elements of the Amazon fan, in: Flood, R.D., Piper, D.J.W., Klaus, A., Peterson, L.C. (Eds.), Proc. ODP Sci. Results 155, pp. 611-651.

Paull, C. K., Ussler, W., Borowski, W. S., 1994. Sources of biogenic methane to form marine gas hydrates, in: Sloan, E. D., Happel, J., Hnatow, M. A. (Eds.), International Conference on Natural Gas Hydrates, Ann. N.Y. Acad. Sci. 715, pp. 392-409.

Popescu, I., Lericolais, G., Panin, N., Wong, H. K., Droz, L., 2001. Late Quaternary channel avulsions on the Danube deep-sea fan. Mar. Geol. 179, 25-37.

Popescu, I., Lericolais, G., Panin, N., Normand, A., Dinu, C., Le Drezen, E., 2004. The Danube submarine canyon (Black Sea): morphology and sedimentary processes. Mar. Geol. 206, 249-265.

Posewang, J., Mienert, J., 1999. The enigma of double BSRs: indicators for changes in the hydrate stability field?. Geo-Mar. Lett. 19, 157-163.

Ross, D. A., 1978. Summary of results of Black Sea drilling, in: Ross, D.A., Neprochnov, Y.P., et al. (Eds.), Initial Reports of the Deep Sea Drilling Project 42/2, US Government Printing Office, Washington, pp. 1149-1178.

Sassen, R., Losh, S. L., Cathles III, L., Roberts, H. H., Whelan, J. K., Milkov, A. V., Sweet, S. T., DeFreitas, D. A., 2001. Massive vein-filling gas hydrate: relation to ongoing gas migration from the deep subsurface in the Gulf of Mexico. Mar. Petr. Geol. $18,551-560$. 
Shipboard Scientific Party ODP Leg 204, 2002. ODP Preliminary Report 204 (available at http://www-odp.tamu.edu/publications/prelim/204_prel/204PREL/PDF).

Sloan, E. D., 1998. Clathrate Hydrates of Natural Gases, Marcel Dekker, New York, 705 pp.

Taylor, M.H., Dillon, W.P., Pecher, I.A., 2000. Trapping and migration of methane associated with the gas hydrate stability zone at the Blake Ridge Diapir: new insights from seismic data. Mar. Geol. 164, 79-89.

Vanneste, M., De Batist, M., Golmstock, A., Kremlev, A., Versteeg, W., 2001. Multifrequency seismic study of gas hydrate-bearing sediments in Lake Baikal, Siberia. Mar. Geol. 172, 1-21.

Vassilev, A., Dimitrov, L., 2002. Spatial and quantity evaluation of the Black Sea gas hydrates. Russ. Geol. Geophys. 43, 672-684.

Wong, H. K., Panin, N., Dinu, C., Georgescu, P., Rahn, C., 1994. Morphology and postChaudian (Late Pleistocene) evolution of the submarine Danube fan complex. Terra Nova 6, 502-511.

Yefremova, A. G., Zhizhchenko, B. P., 1974. Occurrence of crystal hydrates of gas in sediments of modern marine basins. Dokl. Akad. Nauk SSSR 214, 1179-1181.

\section{FIGURE CAPTIONS}

Figure 1. Areas of BSR occurrence in the Danube deep-sea fan A, B, C (shown by light grey shading). Axis of major channel-levee systems are indicated by dark grey shading. Broad tracklines show multiple BSRs, and associated numbers specify how many BSRs occur. Locations of profiles shown in Figures 2, 3, 4 and 6 are indicated. The inset box shows the location of the study zone in the Black Sea. 
Figure 2. Quadruple (quintuple?) BSR across zone B, location in Figure 1.

A: Part of seismic reflection profile b039-GI. Seismic facies are indicated ER=Enhanced Reflections, AT=Acoustic Turbidity. Dashed lines show top and bottom of the channel-levee system. Dotted line shows top of free gas.

B: Interpretation of the seismic image. Grey area is the hydrate stability zone (HSZ), circles indicate free gas. Note that free gas concentrates at the channel axis. Amounts of free gas also occur below BSRs 2, 3 and 4.

Figure 3. Triple BSR across zone B: part of seismic reflection profile b102b-miniGI, location in Figure 1. Seismic facies and limits are indicated as in Figure 2.

Figure 4. Double BSR across zone A: part of seismic reflection profile b038-GI, location in Figure 1. Seismic facies and limits are indicated as in Figure 2.

Figure 5.

A: Detail of the multiple BSRs shown in Figure 2A (display in black-white-red scale). Some of the enhanced reflections change amplitude where they cross BSR1 but also lower BSRs 2, 3 and 4, indicating that free gas occurs locally beneath multiple BSRs. Note the polarity of the sea floor reflection defined as a strong amplitude black phase followed by a red phase, and the reversed polarity of the BSRs marked by a red phase followed by a black phase.

B: Visualization of CDP 4610 of profile b039-GI, showing that multiple BSRs are phase-reversed relative to the sea floor. 
Figure 6. Double BSR along zone C: part of the seismic reflection profile b007-miniGI, location in Figure 1. Seismic facies are indicated as in Figure 2.

Figure 7. Model-derived depth of the BGHSZ for the multiple BSRs shown in Figure 2. Hydrate stability curves are calculated for different gas compositions and pore water salinities, under the present-day P-T conditions. Intersection of the hydrate stability curves with the geothermal gradient (Temperature line) corresponds to the BGHSZ. The depth of each BSR is shown within an error margin, due to imprecise evaluation of the sound velocity in sediments.

A. BSR1 corresponds to the BGHSZ for a gas composition with more than $99 \%$ methane.

B. BSR1 corresponds to the BGHSZ for fresh pore water 0-5\%, considering gas compositions of $100 \%$ methane (solid line) and $99 \%$ methane $+1 \%$ ethane (dotted line).

Figure 8. Model-derived depth of the BGHSZ for the multiple BSRs shown in Figure 2, under the present-day P-T conditions. Variation of the BGHSZ depth is function of the gas hydrate composition. Intersection of the BSR depth with a given curve indicates the gas hydrate composition that could create this BSR.

A. BGHSZ depths for hydrate compositions consisting in mixtures of methane and $\mathrm{CO}_{2}$, $\mathrm{N}_{2}$ and $\mathrm{H}_{2} \mathrm{~S}$ respectively (based on Table 1 in suppl. mat.). BSR4 corresponds to the BGHSZ for hydrates with 5.1-5.6\% $\mathrm{H}_{2} \mathrm{~S}$.

B. BGHSZ depths for hydrate compositions consisting in variable mixtures of methane C1, ethane C2 and propane C3 (based on Table 2 in suppl. mat.). Curves are calculated for 0\% C3 (C1 and C2 only), 1\% C3, 5\% C3 and 10\% C3. The limit between hydrates 
in structure I and structure II is indicated (beyond this limit, C3 does not form hydrate). BSR4 corresponds to the BGHSZ for hydrates with 26.3-28.5\% C2 (for 0-1\% C3), with 5\% C3 in structure II (for 17 to $23.5 \%$ C2), or in structure I (for 37.4 to 47.2 C2), and with 10\% C3 in structure II (for 32 to $34.3 \%$ C2) or in structure I (46 to 50\% C2).

Figure 9. Model-derived depth of the BGHSZ for the multiple BSRs shown in Figure 2, under potential former P-T conditions (based on Table 3 in suppl. mat.). Curves are calculated for sea levels situated at $0,-30,-60,-90,-120$ and $-150 \mathrm{~m}$, and for seafloor temperatures 0 to $5^{\circ} \mathrm{C}$ lower than today, considering a gas composition of $99 \%$ methane, $1 \%$ ethane. $\Delta \mathrm{T}$ is the difference between the current temperature and the paleotemperature at the seafloor. Present conditions correspond to $\Delta \mathrm{T}=0$ for a sea level at $0 \mathrm{~m}$. Intersection of the BSR depth with the curve corresponding to a given sea level, indicates the seafloor paleotemperature. For a sea level at $-90 \mathrm{~m}$ during the last lowstand (Popescu et al., 2004), BSR2 corresponds to a paleotemperature $1.9-2.4{ }^{\circ} \mathrm{C}$ lower than today. For any sea level between 0 and -150 m, BSR3 and BSR4 correspond to paleotemperatures lower than today by $2.9-3.9^{\circ} \mathrm{C}$ and $3.6-4.6^{\circ} \mathrm{C}$ respectively. 


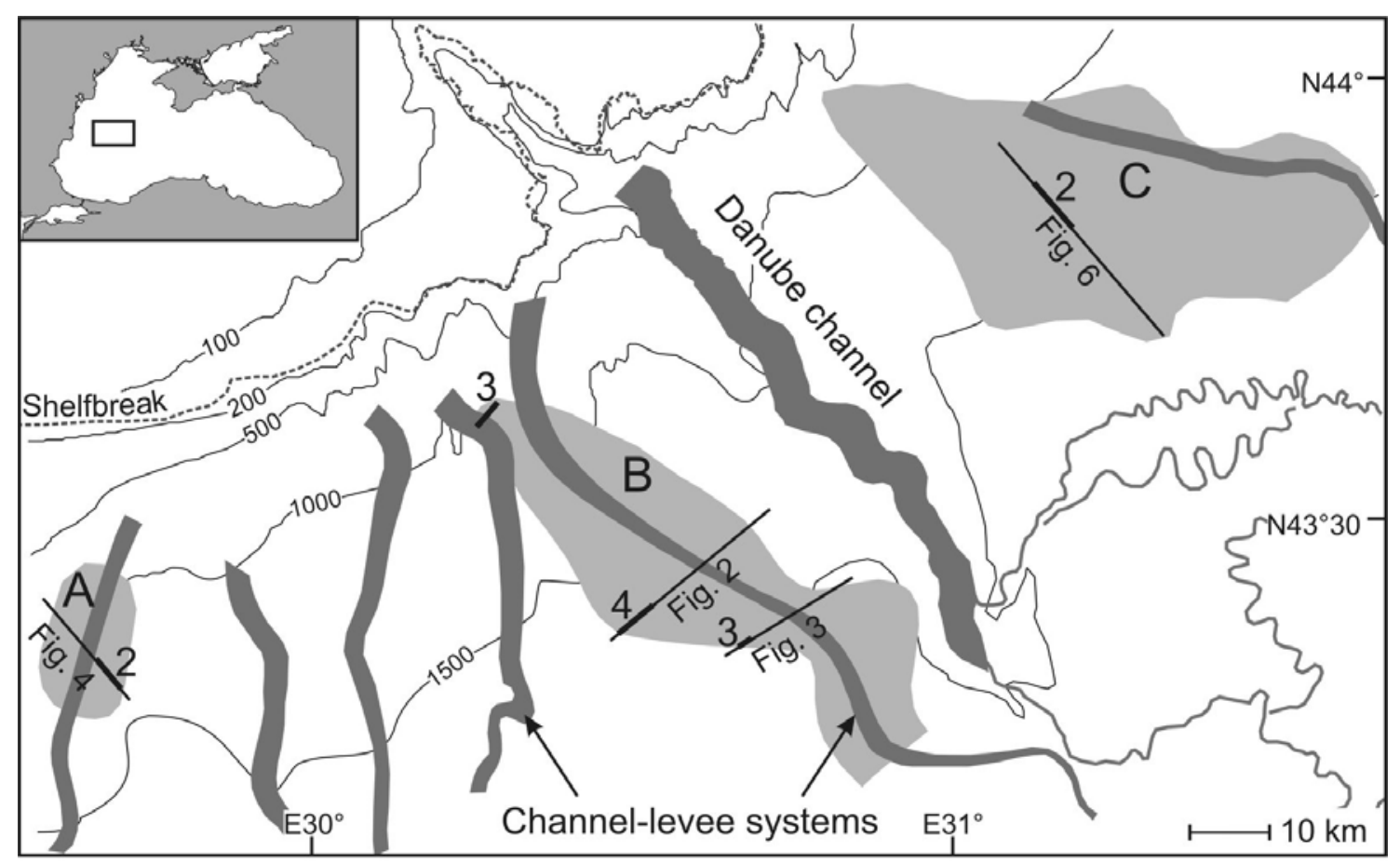

Popescu-figure1 


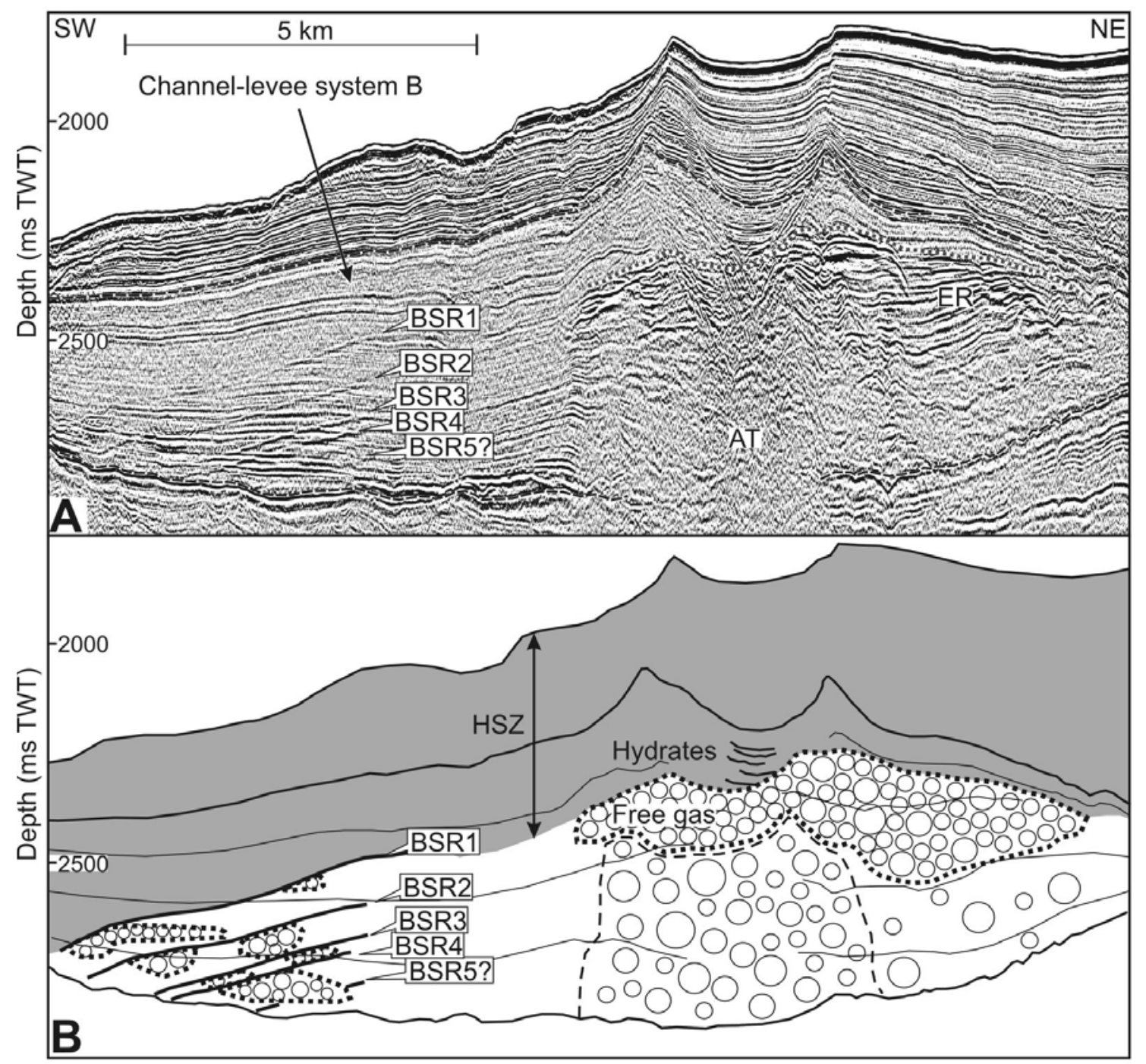

Popescu-figure2 


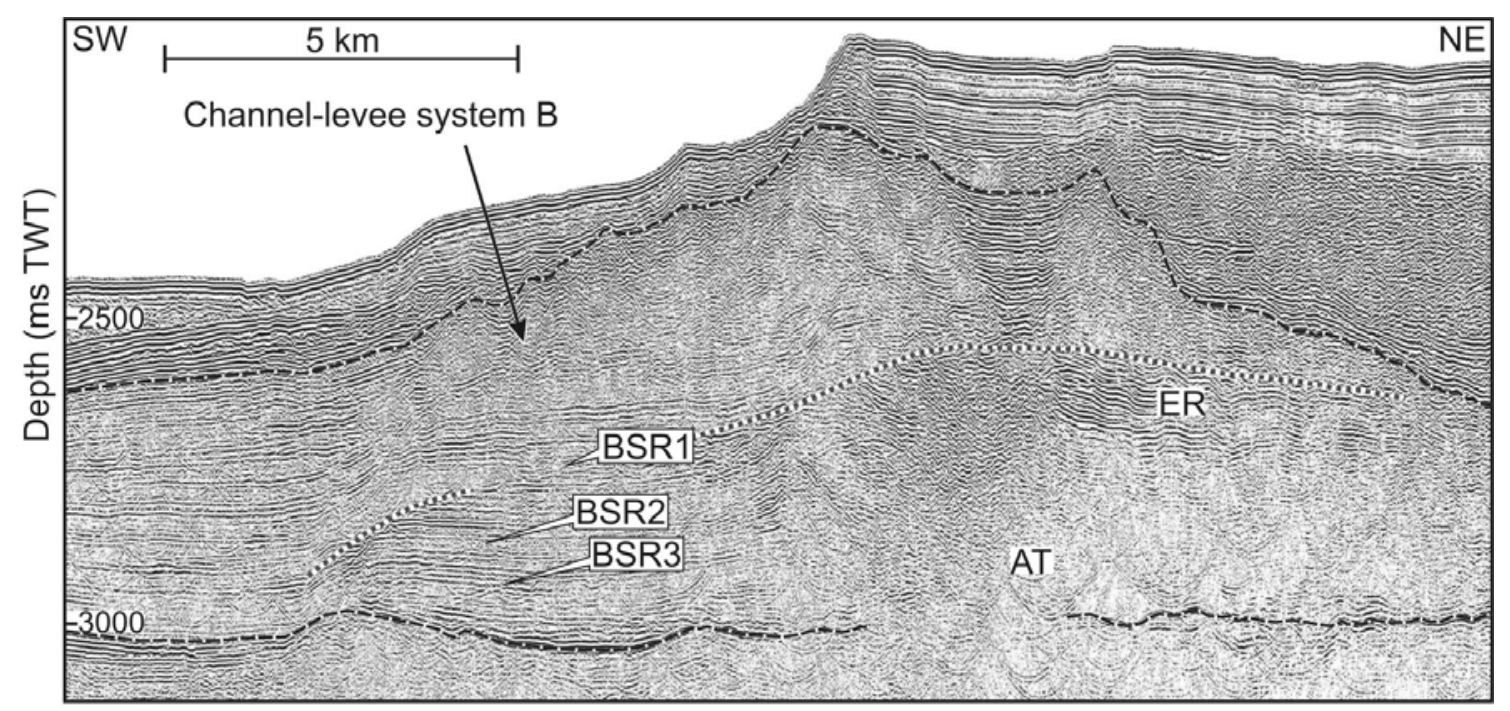

Popescu-figure3 


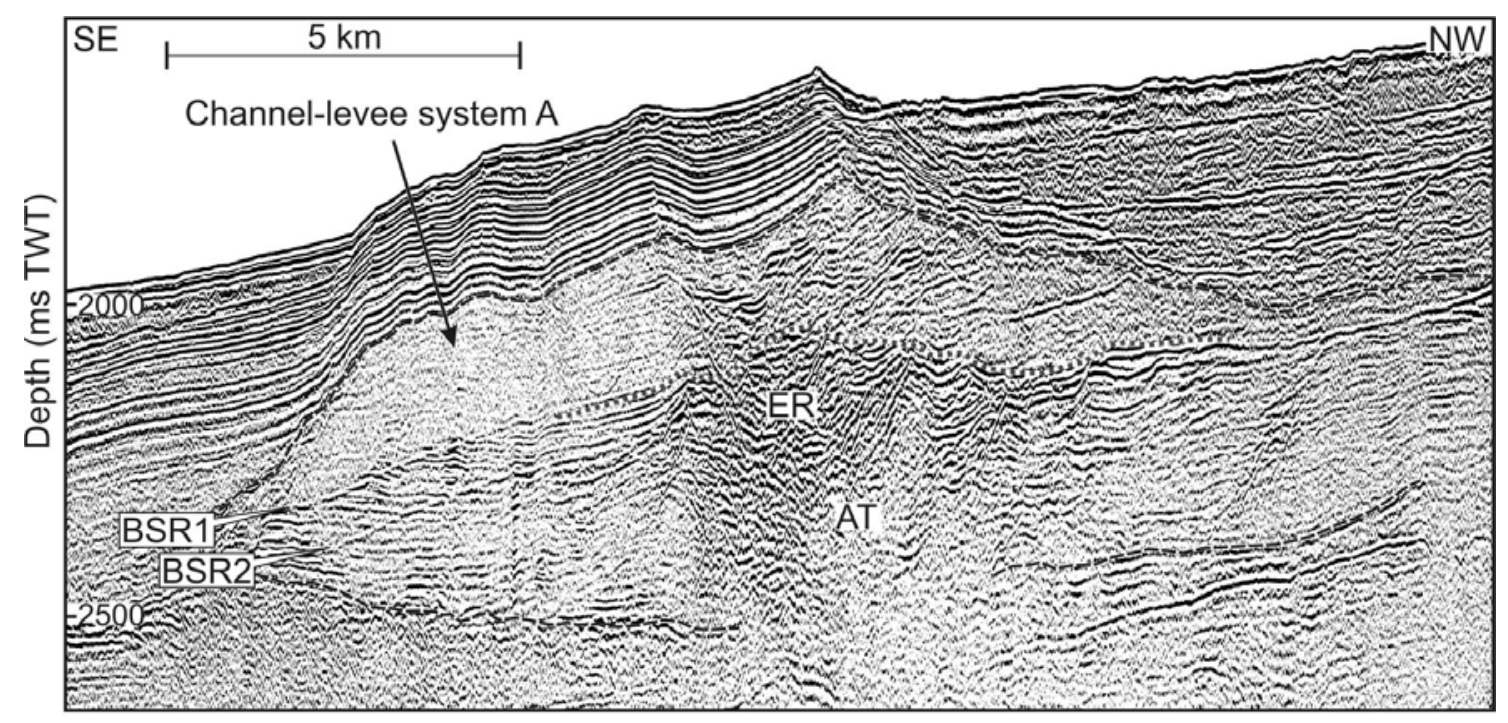

Popescu-figure4 


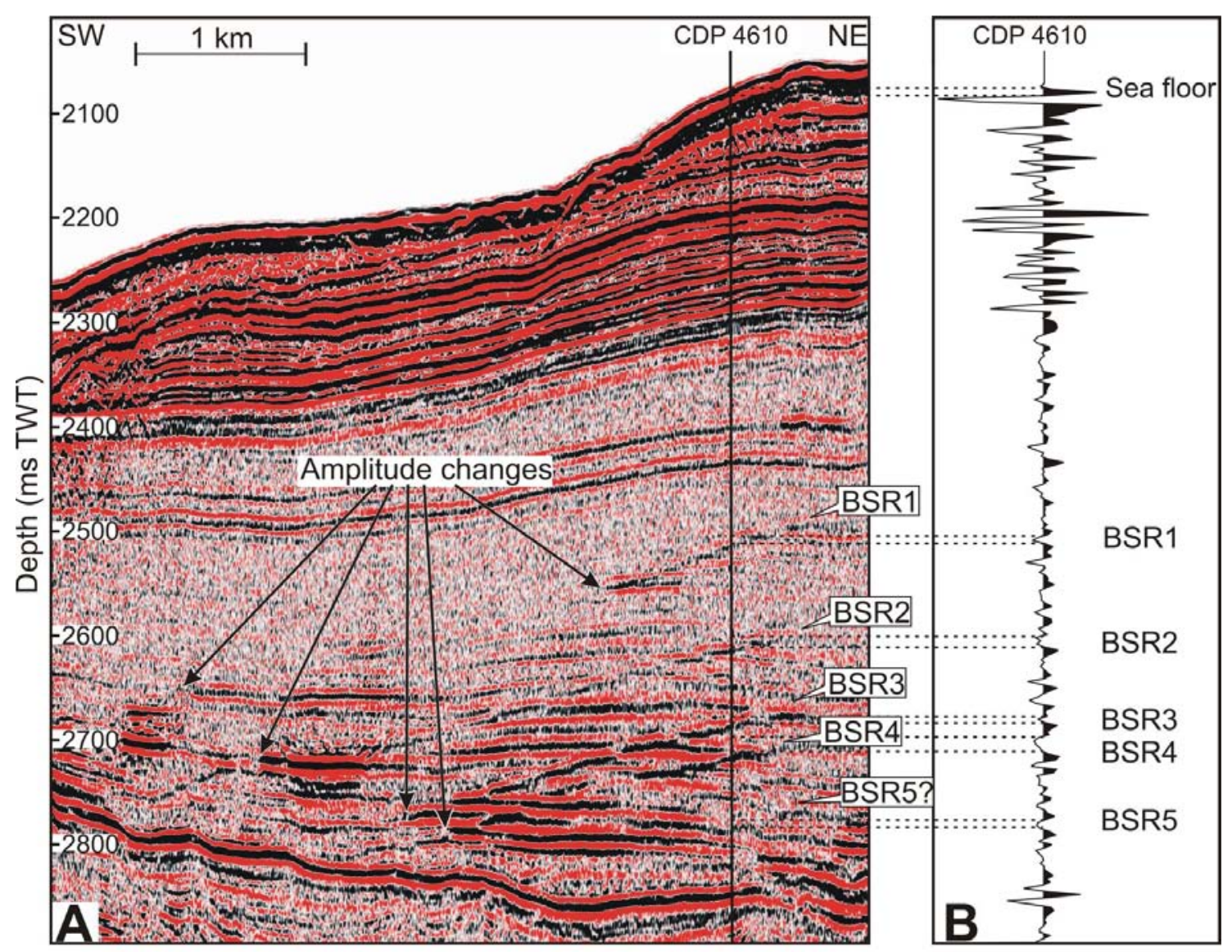

Popescu-figure5 


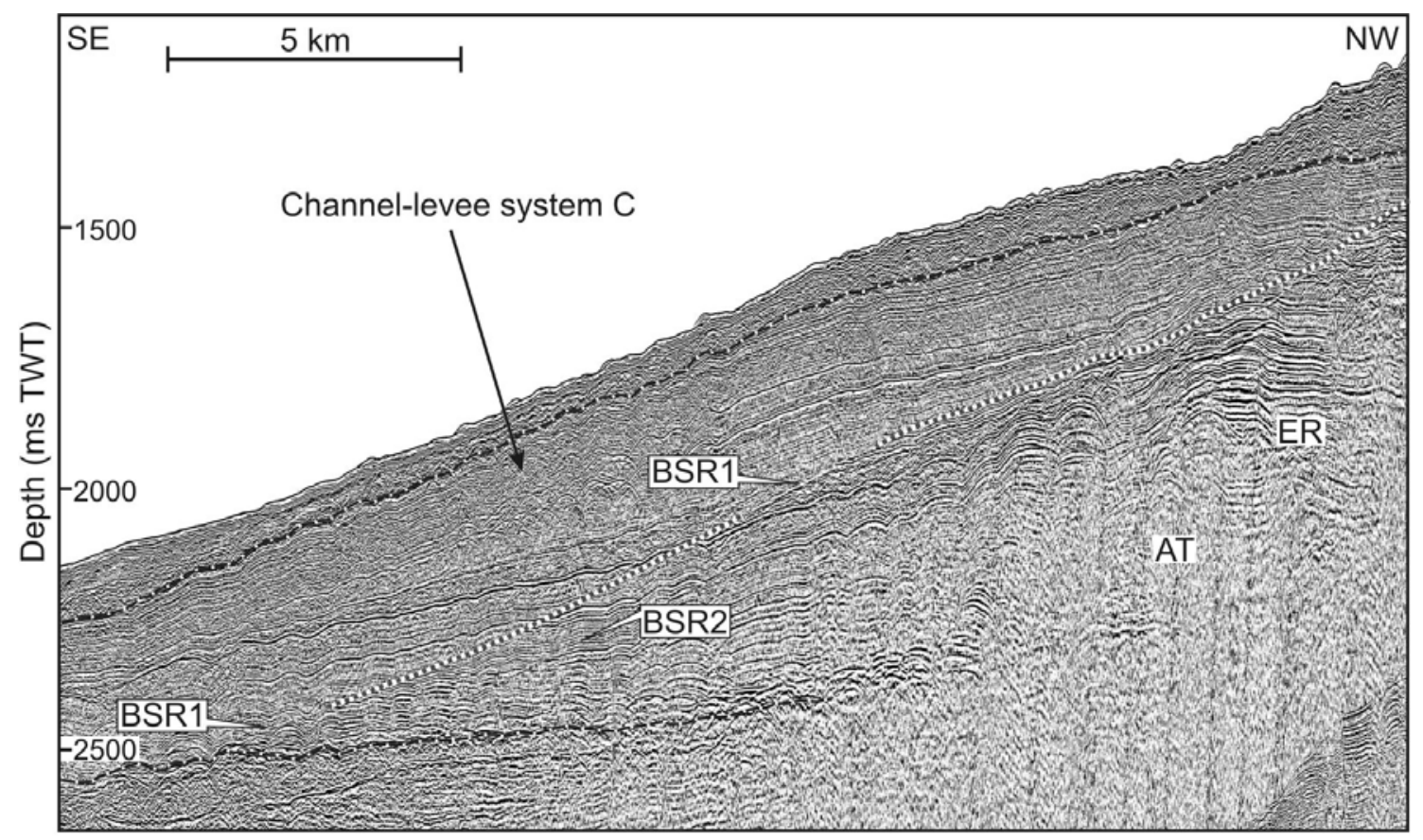

Popescu-figure6 

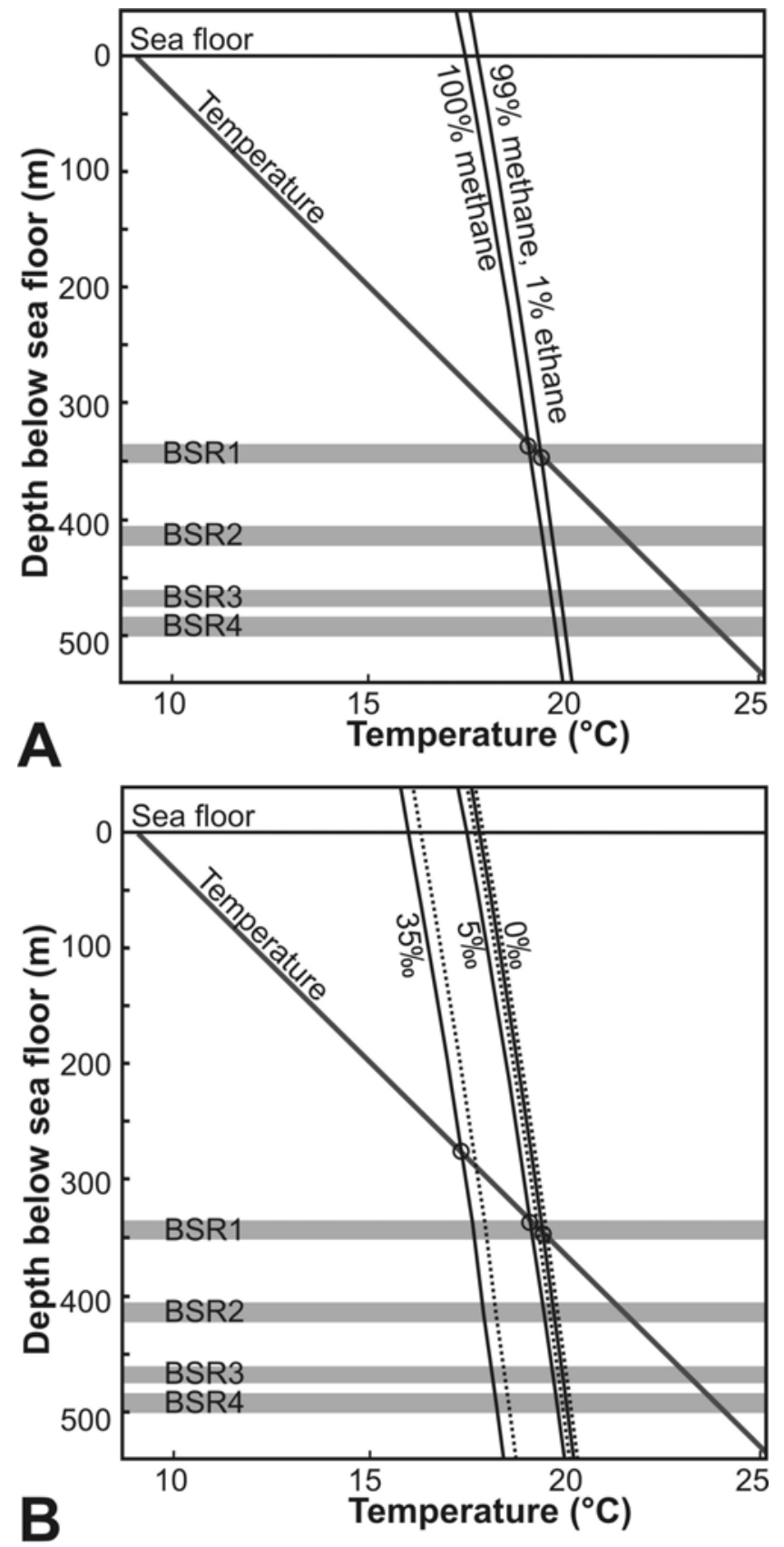

Popescu-figure7 

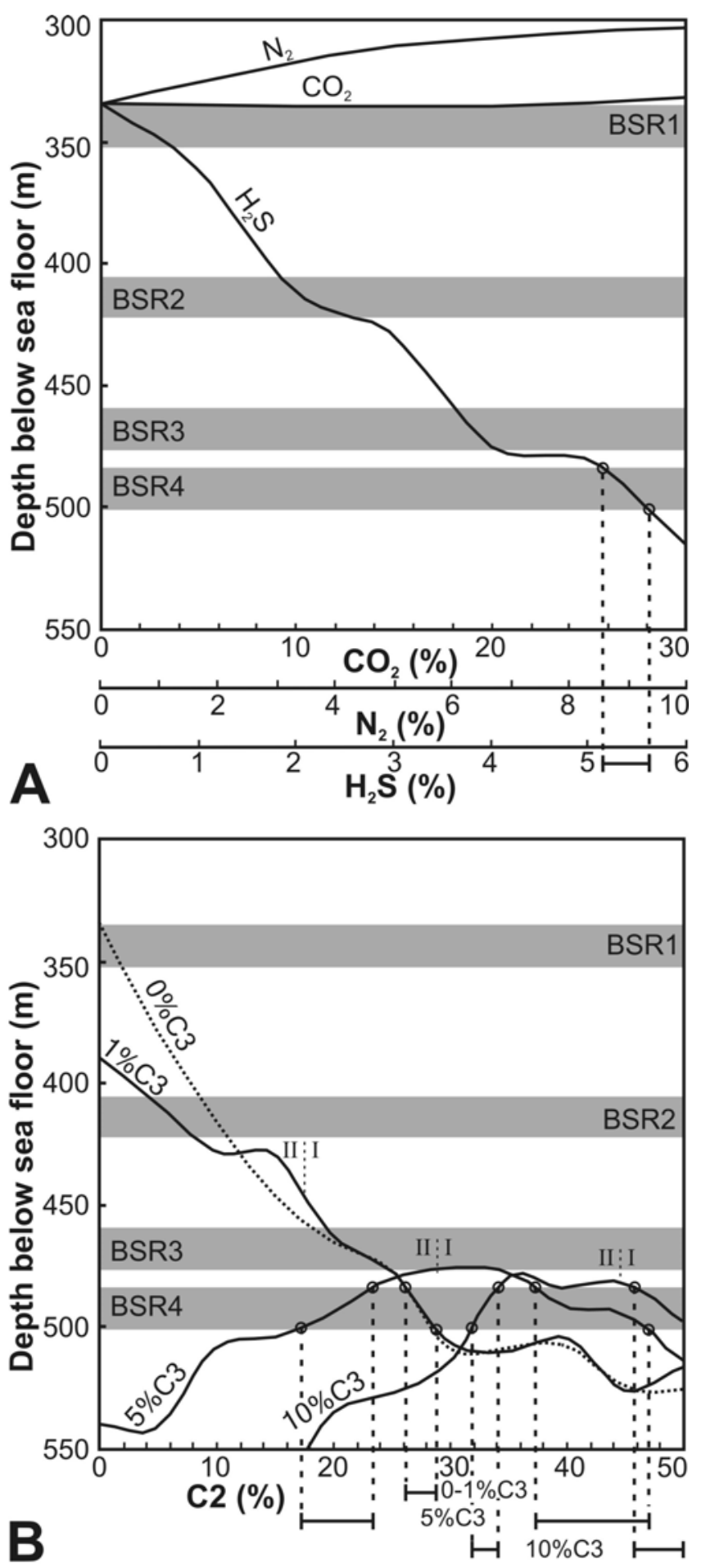

Popescu-figure8 


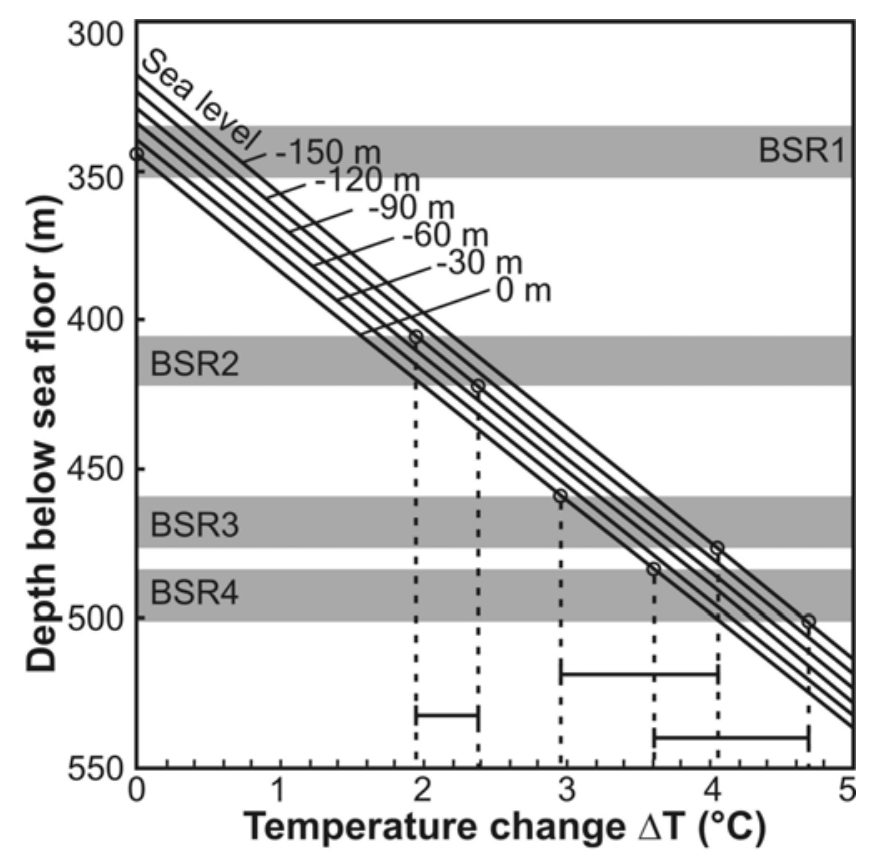

Popescu-figure9 


\section{SUPPLEMENTARY MATERIAL}

TABLES

Table 1.

A.

\begin{tabular}{ll}
\hline $\begin{array}{l}\mathrm{CO}_{2} \\
(\%)\end{array}$ & $\begin{array}{l}\text { Depth of the BGHSZ } \\
(\mathrm{m})\end{array}$ \\
\hline 0 & 334.0 \\
10 & 335.5 \\
20 & 335.5 \\
30 & 332 \\
\hline
\end{tabular}

B.

\begin{tabular}{ll}
\hline $\begin{array}{l}\mathrm{N}_{2} \\
(\%)\end{array}$ & $\begin{array}{l}\text { Depth of the BGHSZ } \\
(\mathrm{m})\end{array}$ \\
\hline 0 & 334.0 \\
5 & 310.5 \\
10 & 303.5 \\
\hline
\end{tabular}

C.

\begin{tabular}{ll}
\hline $\begin{array}{l}\mathrm{H}_{2} \mathrm{~S} \\
(\%)\end{array}$ & $\begin{array}{l}\text { Depth of the BGHSZ } \\
(\mathrm{m})\end{array}$ \\
\hline 0 & 334.0 \\
1 & 361.5 \\
2 & 411.5 \\
3 & 429.5 \\
4 & 475.5 \\
5 & 479.5 \\
6 & 515.0 \\
\hline
\end{tabular}


Table 2.

\begin{tabular}{|c|c|c|c|c|c|c|c|c|c|c|c|}
\hline \multirow[t]{2}{*}{$\begin{array}{l}\text { Propane (C3) } \\
\text { (\%) }\end{array}$} & \multicolumn{11}{|c|}{$\begin{array}{l}\text { Ethane C2 } \\
\text { (\%) }\end{array}$} \\
\hline & 0 & 5 & 10 & 15 & 20 & 25 & 30 & 35 & 40 & 45 & 50 \\
\hline 0 & 334.0 & 378.0 & 416.0 & 446.0 & 464.5 & 477.0 & 509.5 & 508.5 & 507.5 & 524.5 & 525.5 \\
\hline 1 & 389.0 & 407.5 & 428.5 & 429.5 & 462.5 & 476.5 & 506.5 & 510.0 & 504.5 & 526.0 & 516.0 \\
\hline 5 & 539.0 & 541.0 & 508.0 & 504.5 & 494.5 & 479.5 & 475.5 & 476.5 & 492.0 & 494.0 & 514.0 \\
\hline 10 & 628.5 & 597.5 & 593.0 & 571.0 & 535.5 & 527.0 & 514.0 & 479.5 & 483.5 & 481.5 & 497.5 \\
\hline
\end{tabular}

Table 3.

\begin{tabular}{|c|c|c|c|c|c|c|}
\hline \multirow[t]{2}{*}{$\begin{array}{l}\text { Sea level } \\
\text { (m) }\end{array}$} & \multicolumn{6}{|c|}{$\begin{array}{l}\text { Temperature change } \Delta \mathrm{T} \\
\left({ }^{\circ} \mathrm{C}\right)\end{array}$} \\
\hline & 0 & 1 & 2 & 3 & 4 & 5 \\
\hline 0 & $334.0-344.5$ & 373.0-383.5 & $412.0-422.0$ & $450.5-460.5$ & 489.5-499.0 & $527.5-537.0$ \\
\hline-30 & 328.5-339.5 & $368.0-378.5$ & $407.0-417.5$ & $445.5-456.0$ & $484.5-494.5$ & $523.5-532.5$ \\
\hline-60 & 323.5-334.5 & $362.5-373.5$ & $401.5-412.5$ & $440.5-451.0$ & 479.5-489.5 & 518.5-528.5 \\
\hline-90 & $318.0-329.5$ & $357.5-368.5$ & $396.5-407.5$ & $435.5-446.5$ & $474.5-485.0$ & 513.5-523.5 \\
\hline-120 & $312.5-324.0$ & $352.0-363.5$ & $391.5-402.5$ & $430.5-441.5$ & $469.5-480.5$ & 508.5-518.5 \\
\hline-150 & 306.5-318.5 & $346.5-358.0$ & 385.5-397.5 & $425.5-436.5$ & $464.5-475.5$ & 503.5-514.0 \\
\hline
\end{tabular}




\section{SUPPLEMENTARY MATERIAL}

\section{TABLE CAPTIONS}

Table 1. Model-derived depth of the BGHSZ for the multiple BSRs shown in Figure 2. Values are calculated for hydrate compositions consisting in mixtures of methane and $\mathrm{CO}_{2}(\mathrm{~A})$, methane and $\mathrm{N}_{2}(\mathrm{~B})$, and methane and $\mathrm{H}_{2} \mathrm{~S}(\mathrm{C})$.

Table 2. Model-derived depth of the BGHSZ for the multiple BSRs shown in Figure 2. Values are calculated for hydrate compositions consisting in mixtures of methane and different contents of ethane (0 to 50\%) and propane (0 to $10 \%$ ).

Table 3. Model-derived depth of the BGHSZ for the multiple BSRs shown in Figure 2. Values are calculated for paleotemperatures at the sea bottom lower than the present one by $0,1,2,3,4$ and $5^{\circ} \mathrm{C}$, and for sea levels situated at $0,-30,-60,-90,-120$ and -150 $\mathrm{m} . \Delta \mathrm{T}$ is the difference between the current temperature and the paleotemperature at the sea-bottom. The two distinct values of BGHSZ depth correspond to a gas composition of $100 \%$ methane, and $99 \%$ methane $+1 \%$ ethane, respectively. Present conditions correspond to $\Delta \mathrm{T}=0$ for a sea level at $0 \mathrm{~m}$. 


\section{SUPPLEMENTARY MATERIAL}

\section{FIGURE CAPTIONS}

Figure SM1. Detail of the triple BSR shown in Figure 3 (part of seismic reflection profile b102b-miniGI across zone B). BSRs are sub-parallel to the sea floor and crosscut the sedimentary structure. Some of the enhanced reflections corresponding with gascharged layers change amplitude where they cross BSR1 but also lower BSRs 2 and 3, indicating that free gas occurs beneath multiple BSRs. Note that the BSRs are less clear on this profile acquired with a mini-GI source (central frequency $150 \mathrm{~Hz}$ ) compared with GI gun data (central frequency $70 \mathrm{~Hz}$ ) shown in Figures 5 and SM2.

Figure SM2. Detail of the double BSR shown in Figure 4 (part of seismic reflection profile b038-GI across zone A). BSRs are sub-parallel to the sea floor and crosscut the sedimentary structure. Some of the enhanced reflections corresponding with gascharged layers change amplitude where they cross BSR1, indicating that free gas occurs beneath the current BGHSZ.

Figure SM3. Detail of the double BSR shown in Figure 6 (part of seismic reflection profile b0007-miniGI across zone C). BSRs are sub-parallel to the sea floor and crosscut the sedimentary structure. Some of the enhanced reflections corresponding with gascharged layers change amplitude where they cross BSR1, indicating that free gas occurs beneath the current BGHSZ. Note that the BSRs are less clear on this profile acquired with a mini-GI source (central frequency $150 \mathrm{~Hz}$ ) compared with GI gun data (central frequency $70 \mathrm{~Hz}$ ) shown in Figures 5 and SM2. 


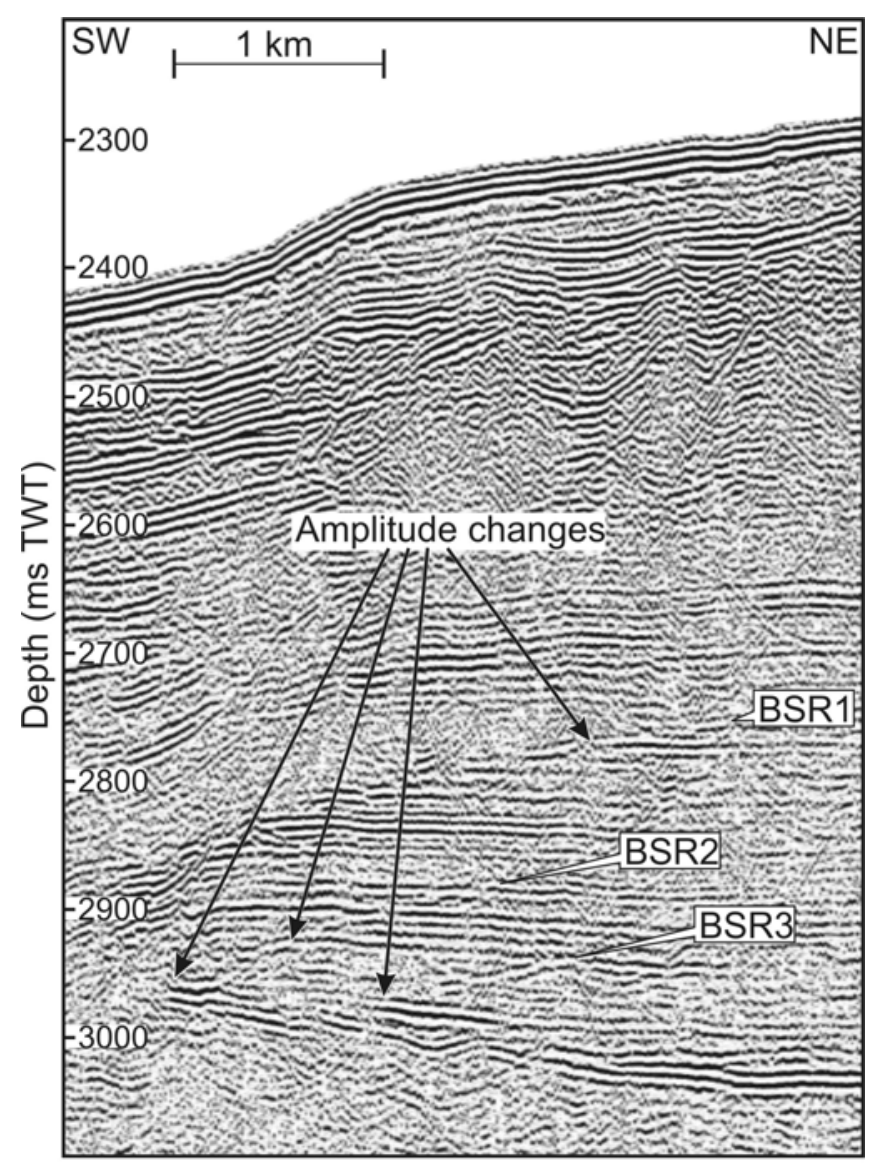

Popescu-figureSM1 


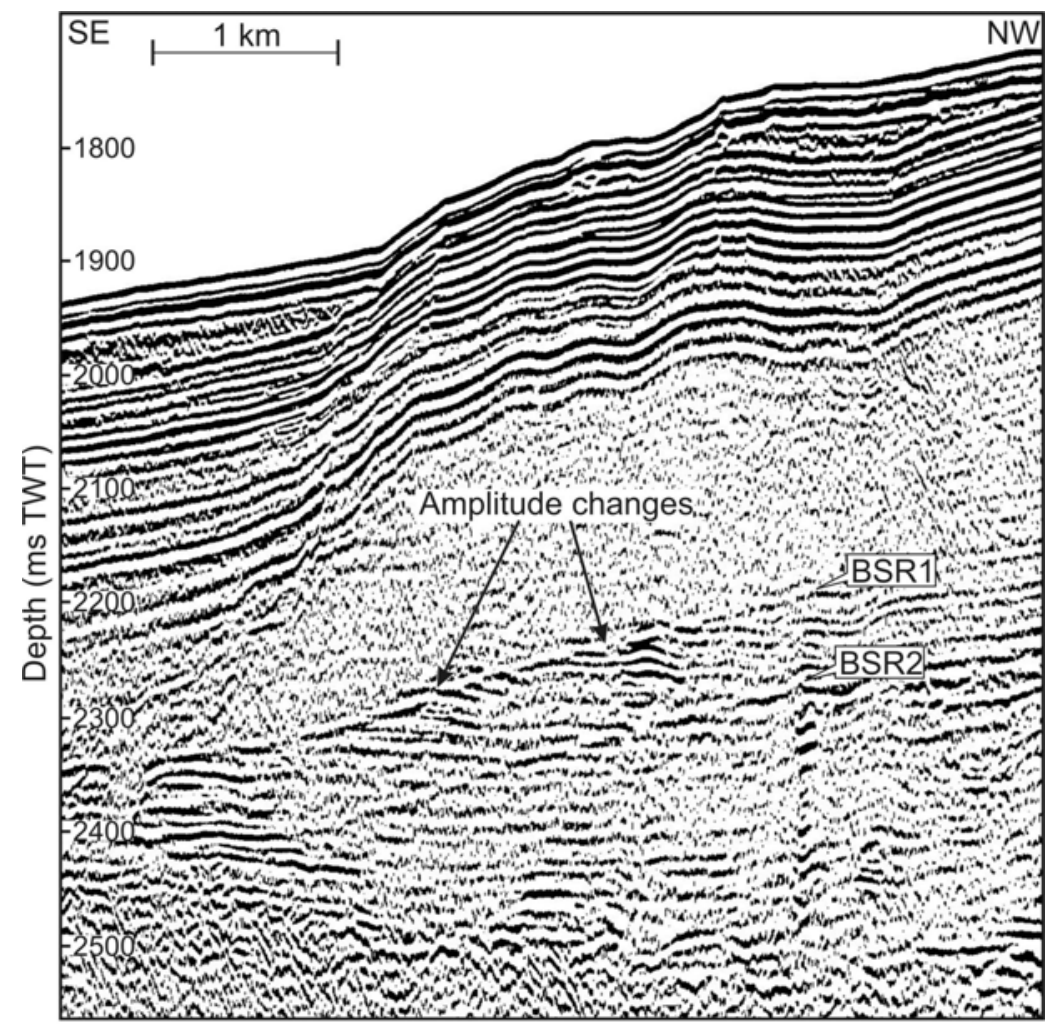

Popescu-figureSM2 


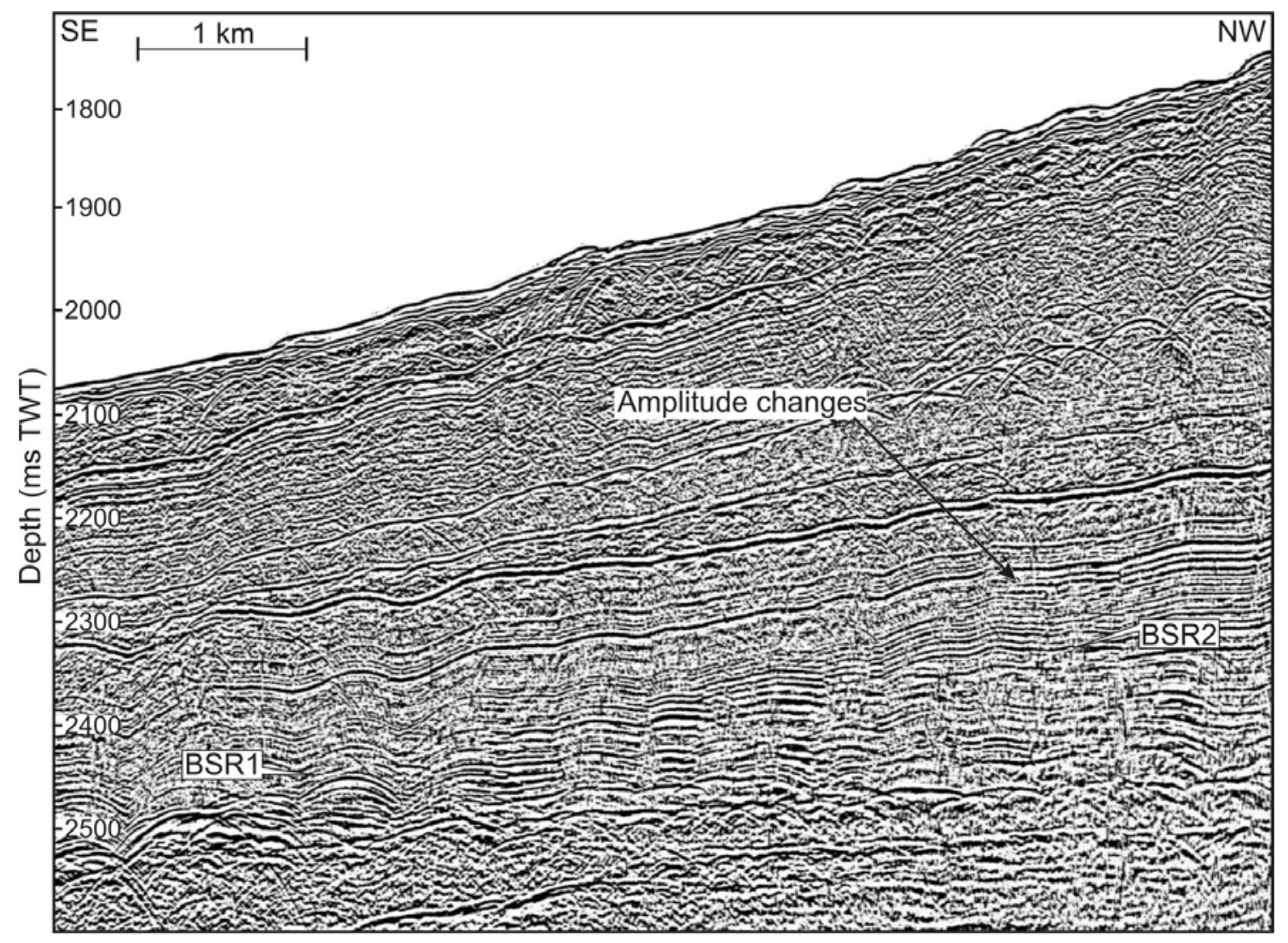

Popescu-figureSM3 